\title{
UTILIZAÇÃO DA SILAGEM DE RESTOS CULTURAIS DO ABACAXIZEIRO EM SUBSTITUIÇÃO À SILAGEM DE CANA-DE-AÇÚCAR NA ALIMENTAÇÃO DE OVINOS
}

\author{
SANDRo CASTRO SANTOS ${ }^{1}$, JULIANO JosÉ DE RESENDE FERNANDES ${ }^{2}$, EdUARdo RodRIGUES \\ CARVAlHO ${ }^{3}$, Vinicius Nunes de Gouvea ${ }^{4}$, Milton Moreira Lima ${ }^{2}$, Miguel JOAQuim \\ DIAS $^{2}$
}

\begin{abstract}
1Pós Graduando da Escola de Veterinária e Zootecnia da UFG, Goiânia, GO, Brasil - sandrozootec@ gmail.com
${ }^{2}$ Professores Doutores da Escola de Veterinária e Zootecnia da UFG, Goiânia, GO, Brasil.

${ }^{3}$ Professor Doutor do Instituto Federal Goiano, Iporá, GO, Brasil

${ }^{4}$ Pos Graduando da Escola Superior de Agricultura Luiz de Queiroz, USP, Piracicaba, SP, Brasil.
\end{abstract}

\begin{abstract}
Avaliou-se a taxa de desaparecimento e a digestibilidade da silagem de restos culturais do abacaxizeiro (SRA) em substituição à silagem de cana-de-açúcar aditivada com $0,5 \%$ de ureia (SC) na alimentação de ovinos. Foram utilizados cinco cordeiros, raça Santa Inês, alocados em delineamento experimental quadrado latino $5 \times 5$, alimentados com dietas contendo $13,5 \%$ de PB e $63,0 \%$ de NDT. Foram avaliadas cinco dietas definidas da seguinte forma: $100 \%$ de SRA: 0\% SC (100A); $75 \%$ SRA: $25 \%$ SC (75A); 50\% SRA: $50 \%$ SC (50A); 25\% SRA: $75 \%$ SC (25A) e 0\% SRA: $100 \%$ SC(0A). Não houve diferença $(\mathrm{P}>0,05)$ entre os tratamentos para consumo de matéria-
\end{abstract} digestibilidade da fibra em detergente neutro (DFDN) com a adição de SRA. Houve aumento $(\mathrm{P}<0,05)$ da taxa de desaparecimento de MS $(\mathrm{Kd}, \% / \mathrm{h})$ do rúmen com a adição de SRA e o $\mathrm{pH}$ ruminal diminuiu $(\mathrm{P}<0,05)$ de forma linear com a adição de SRA. Em função da taxa de desaparecimento de MS do rúmen, digestibilidade e consumo de MS pode-se utilizar a silagem de restos culturais do abacaxizeiro (SRA) em substituição à silagem de cana-de-açúcar+0,5\% ureia (SC) na alimentação de ovinos.

PALAVRAS-CHAVE: frutas tropicais; ovinos; Santa Inês; subprodutos de indústria.

\section{SUBSTITUTION OF SUGARCANE SILAGE BY PINEAPPLE STALK SILAGE (PSS) IN SHEEP FEED}

\section{ABSTRACT}

We evaluated the disappearance rate and the digestibility of pineapple stalk silage (PSS) as a replacement to sugarcane silage added $0.5 \%$ urea (SCS) in sheep feed. We used five non-castrated male Santa Inês lambs, arranged in a $5 \times 5$ Latin Square, fed diets containing $13.5 \% \mathrm{CP}$ and $63 \%$ TDN. We evaluated the following treatments: $100 \%$ PSS:0\% SCS (100P); $75 \%$ PSS:25\%
SCS (75P); $50 \%$ PSS:50\% SCS (50P); $25 \%$ PSS:75\% SCS (25P) and 0\% PSS: $100 \%$ SCS (0P). There were no differences $(\mathrm{P}>0,05)$ among treatments for $\mathrm{DM}$ intake (597.27 g/day), DM digestibility (DMD) and neutral detergent fiber digestibility (NDFD) $(\mathrm{P}>0.05)$ with PSS inclusion. There was an increase in the ruminal digesta dry matter disappearance $(\% / \mathrm{h})$ and a linear decrease in 
ruminal $\mathrm{pH}(\mathrm{P}<0.05)$ with PSS addition. Regarding DM disappearance, digestibility and intake, pineapple stalk

KEYWORDS: byproducts; Santa Ines; sheep; tropical fruit.

\section{INTRODUÇÃO}

Algumas propriedades da região Norte do país têm aproveitado os restos culturais da póscolheita do abacaxizeiro na alimentação dos ruminantes. Do abacaxizeiro, apenas o fruto é comercializado, o que representa $38 \%$ da planta. O restante (folha, caule e raízes) é considerado resíduo agrícola. Sendo assim, têm surgido diversas maneiras de utilização desse material, seja como fenação ou ensilagem, mas sempre com o objetivo de fornecer alimento no período de escassez de forragem.

Os restos culturais do abacaxizeiro podem atingir até 50 toneladas de produção de massa verde por hectare, dependendo da cultivar e densidade do plantio que pode variar entre 33.000 a 55.000 plantas/ha. Além disso, a composição química dos resíduos das plantas do abacaxi apresentou valores de $23,60 \%$ de matéria seca (MS); 6,3\% de proteína bruta (PB); 73,1\% de fibra em detergente neutro (FDN); 7,0\% de lignina e 58,0\% para os nutrientes digestíveis totais (NDT) ${ }^{1}$; portanto, os restos culturais do abacaxizeiro caracterizam-se como alimento rico em fibra e baixo valor proteico.

As comparações entre os restos culturais do abacaxizeiro e a cana-de-açúcar partem do princípio de que são alimentos com baixo valor nutritivo e composição bromatológica semelhantes. Alguns autores avaliaram a composição bromatológica da silagem de cana-de-açúcar sem aditivos e apresentaram valores médios de $25,0 \%$ de $\mathrm{MS}$, $65,0 \%$ de FDN, 4,0 \% de $\mathrm{PB}, 7,0 \%$ de matéria mineral (MM) e 8,0\% de lignina e 55,3\% de NDT ${ }^{2-4}$.

Apesar de a cana-de-açúcar ser um volumoso tradicional, de fácil cultivo e produção de matéria seca elevada, o intuito dos autores foi utilizá-la como parâmetro, em termos de valor nutricional, para aproveitar os resíduos agrícolas do abacaxizeiro na forma de silagem.

Para a determinação do valor nutritivo de uma forragem, além de sua composição química, aspectos relacionados à extensão da digestão e à taxa de fermentação são de grande relevância, uma vez silage may be used as a replacement to sugarcane silage $+0.5 \%$ urea (SCS in sheep feed.

que esses parâmetros estão diretamente envolvidos no controle do consumo voluntário. Esses processos envolvem taxas de passagem de substâncias não digestíveis e turnover (renovação de nutrientes), e abrangem a taxa de digestão e digestibilidade de nutrientes ${ }^{5}$. Portanto, a digestibilidade e a ingestão da matéria seca das forragens são alguns dos atributos que determinam o nível de produção do animal. Esses fatores são influenciados pela proporção de parede celular, pelas estruturas fibrosas que durante os processos de mastigação e digestão são quebrados em partículas menores. Daí a importância dessas medidas para se avaliar os alimentos em questão.

Objetivou-se com este trabalho avaliar a taxa de desaparecimento e a digestibilidade da silagem de restos culturais do abacaxizeiro em substituição à silagem de cana-de-açúcar adicionada de 0,5\% de ureia na alimentação de ovinos.

\section{MATERIAL E MÉTODOS}

O experimento foi conduzido no Departamento de Produção Animal da Escola de Veterinária e Zootecnia da UFG, Goiânia-GO, no período entre abril e julho de 2007. Adotou-se o delineamento em quadrado latino $5 \times 5$ para realização do experimento. Foram realizados cinco períodos experimentais de 19 dias cada, sendo 10 dias para adaptação às rações e nove dias de avaliação e colheita de amostras. O processo de ensilagem foi realizado no município de Dois Irmãos - TO, em outubro de 2006, em sacos plásticos com capacidade de $30 \mathrm{~kg}$, com o objetivo de facilitar o transporte. A silagem foi compactada com os pés e os sacos foram lacrados e armazenados para posterior abertura. As plantas do abacaxizeiro Ananas comosus cv. pérola possuíam idade aproximada de 36 meses, foram colhidas 60 dias após a colheita do fruto e trituradas por duas vezes, com o objetivo de reduzir o tamanho das partículas (tamanho médio de partícula de 31,8 $\mathrm{mm}$ ), até o material adquirir aspecto de "estopa" (presença das partículas pequenas e fibras longas sob forma de fio) (Figura 1, Tabela1). 


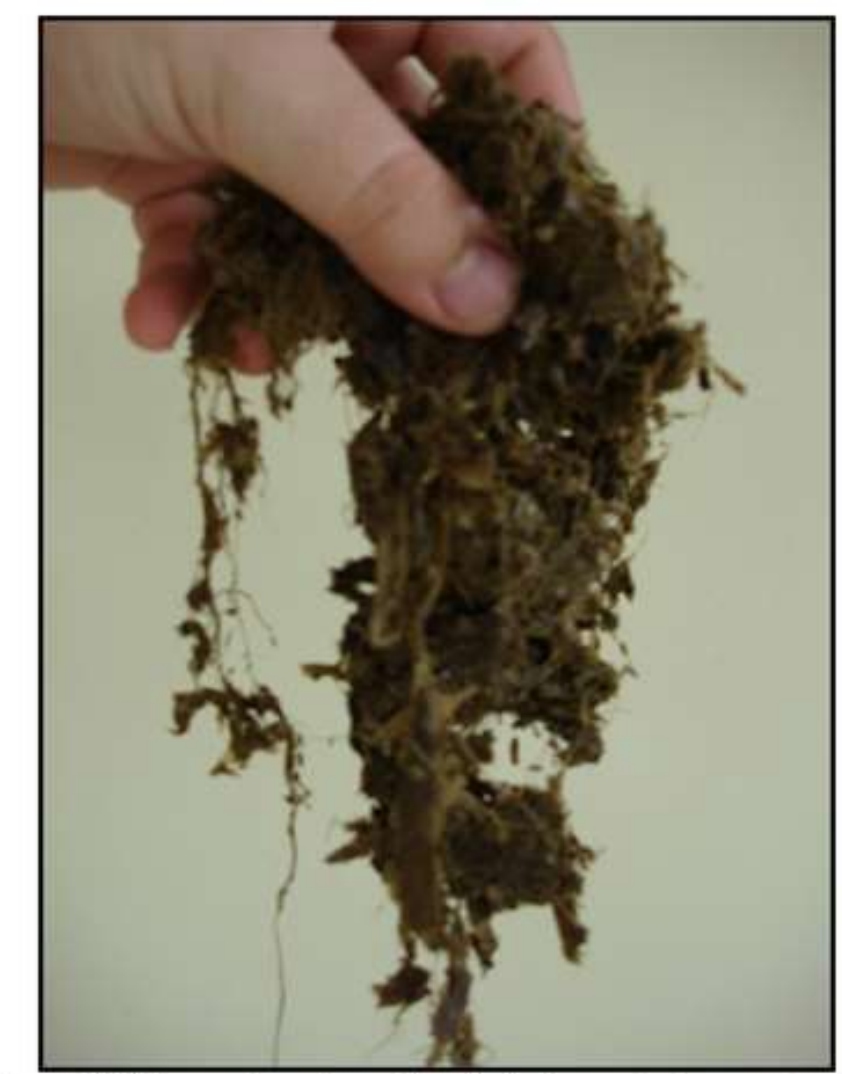

Figura 1. Silagem de restos culturais do abacaxizeiro aspecto de "estopa"

Fonte: Arquivo pessoal

Tabela 1. Composição química e tamanho de partículas $(\mathrm{mm})$ da silagem de restos culturais do abacaxizeiro e silagem de cana-de-açúcar

\begin{tabular}{|c|c|c|}
\hline Nutrientes & $\begin{array}{c}\text { Silagem de restos culturais } \\
\text { do abacaxizeiro }\end{array}$ & $\begin{array}{c}\text { Silagem de } \\
\text { cana-de-açúcar }\end{array}$ \\
\hline Matéria seca (\%MS) & 21,6 & 25,7 \\
\hline Proteína bruta $(\% \mathrm{~PB})$ & 7,1 & 4,7 \\
\hline Fibra em detergente neutro (\%FDN) & 35,5 & 54,3 \\
\hline Carboidratos não fibrosos $(\% \mathrm{CNF})^{1}$ & 21,1 & 36 \\
\hline Matéria Mineral (\%MM) & 3,8 & 3,0 \\
\hline Tamanho médio de partículas $(\mathrm{mm})^{2}$ & 31,8 & 22,5 \\
\hline
\end{tabular}

$1 \mathrm{CNF}=100-(\% \mathrm{~PB}+\% \mathrm{MM}+\% \mathrm{EE}+\% \mathrm{FDN})$

2 Utilizada a metodologia "Penn State Forage and Total Mixed Ration Particle Separator "6

A silagem de cana-de-açúcar variedade IAC 86-2480 foi colhida com 18 meses de idade, picada em ensiladeira, aditivada com $0,5 \%$ ureia com base na $\mathrm{MN}$ e armazenada em manilhas tipo concreto com capacidade de $600 \mathrm{~kg}$ cada. A forragem foi manualmente depositada em camadas de aproximadamente $30 \mathrm{~cm}$ no interior do silo, espalhada e aplicada a ureia e, em seguida, compactada com os pés.
Os tratamentos usados para avaliação foram: $100 \mathrm{~A}$ - 100\% silagem de restos culturais do abacaxizeiro; $75 \mathrm{~A}$ - 75\% silagem de restos culturais do abacaxizeiro:25\% silagem de cana-de-açúcar; $50 \mathrm{~A}$ - $50 \%$ silagem de restos culturais do abacaxizeiro:50\% silagem de cana-de-açúcar; 25A $25 \%$ silagem de restos culturais do abacaxizeiro: $75 \%$ silagem de cana-de-açúcar; 0A - 100\% silagem de cana-de-açúcar, como volumoso na dieta. 
Foram utilizados cinco borregos, machos não castrados, da raça Santa Inês, com média de oito meses de idade e peso vivo $30,2 \mathrm{~kg} \pm 4,8 \mathrm{~kg}$. Os animais foram canulados no rúmen e permaneceram todo o experimento com bolsas coletoras de fezes e alojados em baias individuais medindo $0,60 \times 1,20 \mathrm{~m}$, com piso ripado e provido de bebedouro e comedouro em galpão coberto.
Ao início do período de adaptação, os animais foram pesados, everminados e receberam aplicação subcutânea de $3 \mathrm{~mL}$ de complexo vitamínico ADE.

As dietas (Tabela 2) isoproteicas (13,5\% PB e $63 \%$ NDT), com a relação volumoso:concentrado de 60:40, foram formuladas para suprir as exigências dos ovinos?.

Tabela 2. Percentagem dos ingredientes e composição química das rações

\begin{tabular}{|c|c|c|c|c|c|}
\hline \multirow[t]{2}{*}{ Ingredientes } & \multicolumn{5}{|c|}{ Tratamentos $(\%)^{1}$} \\
\hline & $100^{\mathrm{a}}$ & $75 \mathrm{~A}$ & $50 \mathrm{~A}$ & $25 \mathrm{~A}$ & $0 \mathrm{~A}$ \\
\hline Silagem de restos culturais abacaxi & 60,0 & 45,0 & 30,0 & 15,0 & - \\
\hline Silagem de cana-de-açúcar & - & 15,0 & 30,0 & 45,0 & 60,0 \\
\hline Farelo de soja & 16,1 & 15,93 & 15,60 & 15,67 & 15,67 \\
\hline Milho moído & 18,3 & 18,20 & 18,90 & 18,98 & 19,36 \\
\hline Farelo de Trigo & 2,5 & 2,50 & 2,50 & 2,35 & 1,98 \\
\hline \multirow[t]{2}{*}{ Mistura mineral $^{2}$} & 3,0 & 3,0 & 3,0 & 3,0 & 3,0 \\
\hline & \multicolumn{5}{|c|}{ Composição química (\%) } \\
\hline Matéria seca (\%MS) & 29,25 & 30,86 & 30,72 & 31,24 & 31,05 \\
\hline Nutrientes digestíveis totais $(\% \mathrm{NDT})^{3}$ & 63,74 & 63,40 & 63,19 & 63,00 & 63,00 \\
\hline Proteína bruta $(\% \mathrm{~PB})$ & 13,59 & 13,57 & 13,46 & 13,50 & 13,50 \\
\hline Fibra em detergente neutro (\%FDN) & $36,20^{\mathrm{a}}$ & $42,60^{\mathrm{ab}}$ & $43,11^{\mathrm{b}}$ & $45,42^{\mathrm{b}}$ & $49,15^{b}$ \\
\hline $\mathrm{Ca}$ & 0,87 & 0,83 & 0,78 & 0,73 & 0,69 \\
\hline $\mathrm{P}(\% \mathrm{MS})$ & 0,36 & 0,32 & 0,29 & 0,25 & 0,21 \\
\hline
\end{tabular}

${ }^{a}$ Médias seguidas por letras iguais na mesma linha não diferem entre si $(\mathrm{P}>0,05)$

${ }^{1} 100 \mathrm{~A}-100 \%$ silagem de restos culturais do abacaxizeiro $+0 \%$ silagem de cana-de-açúcar c/0,5\% ureia

$75 \mathrm{~A}-75 \%$ silagem de restos culturais do abacaxizeiro $+25 \%$ silagem de cana-de-açúcar c/0,5\% ureia

50A- $50 \%$ silagem de restos culturais do abacaxizeiro $+50 \%$ silagem de cana-de-açúcar c $/ 0,5 \%$ ureia

$25 \mathrm{~A}-25 \%$ silagem de restos culturais do abacaxizeiro $+75 \%$ silagem de cana-de-açúcar c/0,5\% ureia

0A- $0 \%$ silagem de restos culturais do abacaxizeiro $+100 \%$ silagem de cana-de-açúcar c/0,5\% ureia

${ }^{2}$ Composição da mistura mineral: $12 \% \mathrm{Ca} ; 8,7 \% \mathrm{P} ; 14,7 \% \mathrm{Na} ; 1,8 \% \mathrm{~S} ; 0,059 \% \mathrm{Cu} ; 0,004 \% \mathrm{Co} ; 0,002 \% \mathrm{Cr} ; 0,18 \% \mathrm{Fe} ; 0,008 \% \mathrm{I}$;

$0,13 \% \mathrm{Mn} ; 0,0015 \%$ Se; $0,38 \% \mathrm{Zn} ; 0,03 \%$ Mo

$3 \%$ NDT estimado 7

Os animais receberam as rações experimentais em mistura total ad libitum, duas vezes ao dia, em quantidade suficiente para permitir cerca de $10 \%$ de sobras. As quantidades de ração fornecida, bem como as sobras, eram quantificadas diariamente, para cálculo e ajuste da ingestão de MS dos animais. O cálculo dos nutrientes efetivamente consumidos foi realizado descontando-se dos nutrientes fornecidos o teor de nutrientes das sobras.

Durante cada período experimental, procedeu-se diariamente à amostragem da dieta total fornecida e das sobras ( $20 \%$ do resíduo total diário). As amostras foram mantidas congeladas para formação, ao final do período, de uma amostra composta para cada tratamento e em cada período experimental.
A colheita total de fezes para determinação da digestibilidade aparente de nutrientes foi realizada durante o $12^{\circ}$ ao $16^{\circ}$ dia do período de avaliação. As fezes foram recolhidas nas sacolas coletoras, pesadas e amostradas em $20 \%$ do total excretado. Essas amostras foram armazenadas em sacos plásticos e congeladas sendo que, ao final de cada período de avaliação, as amostras foram homogeneizadas e retirou-se uma sub-amostra por tratamento, de aproximadamente $500 \mathrm{~g}$, para serem secas em estufa de ventilação forçada à $55^{\circ} \mathrm{C}$.

O cálculo da digestibilidade aparente de nutrientes da ração fornecida aos animais foi realizado conforme a equação ${ }^{8}$ : 
Divap $=\frac{[(\text { MSof } * \text { TNof })-(\text { MSsob } * \text { TNsob })]-(\text { MSf * TNf })]}{[(\text { MSof } * \text { TNof })-(\text { MSsob } * \text { TNsob })]} \times 100$

em que,

nutriente (\%);

Divap $=$ Digestibilidade aparente do

MSof = Quantidade de matéria seca oferecida $(\mathrm{kg})$;

TNof $=$ Teor do nutriente na MS oferecida

$(\%)$

sobras (kg);

MSsob = Quantidade de matéria seca das

TNsob $=$ Teor do nutriente na MS das sobras $(\%)$

$(\mathrm{kg})$;

MSf = Quantidade de matéria seca fecal

$\mathrm{TNf}=$ Teor do nutriente na MS fecal $(\%)$.

Procedeu-se o esvaziamento do conteúdo ruminal, em cada período, duas horas antes da alimentação no $18^{\circ}$ dia e, em seguida, no $19^{\circ}$ dia, 2 horas após a alimentação ${ }^{9}$. Para facilitar a coleta de sub-amostras, o conteúdo foi espremido em pano de algodão com as mãos e com o uso de uma peneira (5 $\mathrm{mm}$ de poros) para separação de sólidos e líquidos. Foram retiradas sub-amostras de aproximadamente $200 \mathrm{~g}$ ou $5 \%$ do peso total de sólidos e líquidos, reconstituídas e, em seguida, foram secas em estufa a $55^{\circ} \mathrm{C}$, por 48 horas.

Após as amostragens, o conteúdo ruminal foi imediatamente devolvido ao rúmen e, visando proporcionar adaptação mais rápida à nova dieta, trocaram-se aproximadamente $50 \%$ do conteúdo total entre os carneiros no segundo dia de coleta ou $19^{\circ}$ da avaliação. A massa de conteúdo ruminal foi obtida somando-se os pesos das frações de sólidos e líquidos. $\mathrm{O}$ volume de líquidos foi estimado descontando-se do peso total do conteúdo ruminal a massa de MS (kg), assumindo uma densidade de 1,0 $\mathrm{kg} / \mathrm{L}$ para a fração líquida.

As taxas de desaparecimento $(\mathrm{Kd})$ e tempo de renovação $(\mathrm{Kt})$ da $\mathrm{MS}$ e $\mathrm{FDN}$ no rúmen foram calculadas de acordo com a seguinte equação ${ }^{10}$ :

$\% \mathrm{Kd}=\left[\frac{(\text { consumo de MS ou FDN, } \mathrm{g} / \mathrm{dia})}{\text { (conteúdo ruminal de MS ou FDN, } \mathrm{kg})}\right] \times \frac{1}{24}$

$\mathrm{Kt}(\mathrm{h})=\left[\frac{1}{\% \mathrm{Kd}}\right] \times 100$

As amostras secas do conteúdo ruminal, dietas totais fornecidas, sobras e fezes foram moídas em moinhos tipo Willey com crivos de $1 \mathrm{~mm}$. Depois de moídas, as amostras foram para a estufa por 12 horas a $105{ }^{\circ} \mathrm{C}$ para determinação da matéria seca definitiva ${ }^{11}$. As concentrações da FDN do conteúdo ruminal foram determinadas de acordo com MERTENS $^{12}$, utilizando-se solução de ureia 8M e amilase termoestável (Sigma3306; Sigma ChemicalCo., St.Louis,MD).

Para a aferição do $\mathrm{pH}$, amostras do conteúdo ruminal (aproximadamente $50 \mathrm{~g}$ ) foram tomadas em diferentes pontos no rúmen. A primeira amostragem ocorreu imediatamente antes da oferta de alimento matinal (08:00 horas), e as amostras subsequentes foram colhidas a cada duas horas durante 12 horas, sendo os tempos estabelecidos de 2, 4, 6, 8, 10 e 12 horas após o fornecimento da ração do período da manhã. $O$ conteúdo ruminal foi filtrado sob pressão manual em tecido de algodão, o líquido foi homogeneizado e o seu valor de $\mathrm{pH}$ foi imediatamente mensurado por meio de leitura em potenciômetro digital DIGIMED - DMPH2. Após a aferição, a parte sólida e líquida foram homogeneizadas e devolvidas ao rúmen.

A análise estatística dos dados foi realizada utilizando-se o PROC GLM $^{13}$, sendo que a comparação das médias entre os tratamentos foram feitas por contrastes ortogonais completos, considerando-se o nível de significância de $5 \%$.

\section{RESULTADOS E DISCUSSÃO}

Os consumos de matéria seca (CMS) 636,36 $\mathrm{g} / \mathrm{dia} ; \quad 629,90 \mathrm{~g} / \mathrm{dia} ; 560,53 \mathrm{~g} / \mathrm{dia} ; 576,80 \mathrm{~g} / \mathrm{dia}$; $582,74 \mathrm{~g} / \mathrm{dia}$, para os tratamentos 100A, 75A, 50A, $25 \mathrm{~A}, 0 \mathrm{~A}$, respectivamente (Tabela 3 ), não diferiram significativamente $(P>0,05), \quad o$ que pode ser justificado pelo balanceamento da dieta para os nutrientes digestíveis totais (NDT), evitando-se a limitação do consumo por energia, e também pela DMS não ter apresentado diferença $(\mathrm{P}>0,05)$.

$\mathrm{O}$ consumo de FDN (CFDN) das rações experimentais permaneceu similar $(\mathrm{P}>0,05$, Tabela 3 ), embora os teores de fibra tenham diferido $(\mathrm{P}<0,05)$ entre os tratamentos (Tabela 2), sendo esses maiores para as dietas contendo SC. A digestibilidade de fibra em detergente neutro (DFDN) e digestibilidade de fibra em detergente ácido (DFDA) (Tabela 3) não diferiram (P>0,05) entre os tratamentos. Mesmo com os menores $(\mathrm{P}<0,05)$ teores de FDN e FDA para os tratamentos contendo SRA (Tabela 2) e a forma como foram processadas essas silagens não foram suficientes para afetar a digestibilidade das fibras.

Mertens e Ely ${ }^{14}$ propuseram um modelo de desaparecimento de fibra da área digestiva em ruminantes, baseado na taxa e na extensão da digestão de forragens no rúmen. Os autores sugeriram que o consumo máximo de MS digestível seja afetado mais pela proporção de fibra indigestível 
e taxa de passagem do que pela taxa de digestão de fibra

Houve redução $(\mathrm{P}<0,05)$ da taxa de desaparecimento de MS $(\% / \mathrm{h})$ do rúmen com a adição de SC. Os valores apresentados são $8,08 \% / \mathrm{h} ; 8,31 \% / \mathrm{h}$; $5,85 \% / \mathrm{h} ; 6,49 \% / \mathrm{h} ; 7,03 \% / \mathrm{h}$, para os tratamentos $100 \mathrm{~A}, 75 \mathrm{~A}, 50 \mathrm{~A}, 25 \mathrm{~A}$ e $0 \mathrm{~A}$, respectivamente. A taxa de desaparecimento é em função da taxa de passagem e taxa de digestão; assim, quando a ingestão de alimento aumenta, a taxa de passagem aumenta e o tamanho das partículas que deixam o rúmen também podem ser maiores ${ }^{5}$. Não houve aumento $(\mathrm{P}>0,05)$ no $\mathrm{CMS}$ entre os tratamentos, a taxa de desaparecimento da MS para os tratamentos contendo a SRA foram maiores $(\mathrm{P}<0,05)$; portanto, pode-se dizer que a taxa de digestão da MS da SRA foi menor para os tratamentos contendo essa silagem.

Tabela 3- Médias de consumo, taxa de desaparecimento e $\mathrm{pH}$ das dietas contendo silagem de restos culturais do abacaxizeiro substituídas por quantidades crescentes de silagem de cana-de-açúcar com $0,5 \%$ de ureia

\begin{tabular}{|c|c|c|c|c|c|c|c|c|c|c|}
\hline \multirow[t]{2}{*}{ Variáveis ${ }^{3}$} & \multicolumn{5}{|c|}{ Tratamentos $^{1}$} & \multicolumn{4}{|c|}{ Efeitos $^{2}$} & \multirow[b]{2}{*}{$\mathrm{CV}(\%)$} \\
\hline & $100 \mathrm{~A}$ & $75 \mathrm{~A}$ & $50 \mathrm{~A}$ & $25 \mathrm{~A}$ & $\overline{0 A}$ & Lin & Quad & Cub & Quar & \\
\hline CMS(g/dia) & 636,36 & 629,90 & 570,38 & 576,82 & 566,98 & NS & NS & NS & NS & 15,16 \\
\hline CFDN(g/dia) & 259,88 & 248,12 & 242,80 & 277,37 & 256,39 & NS & NS & NS & NS & 23,62 \\
\hline $\operatorname{DMS}(\%)$ & 66,58 & 66,53 & 65,12 & 59,49 & 61,75 & NS & NS & NS & NS & 11,83 \\
\hline $\operatorname{DFDN}(\%)$ & 54,86 & 56,85 & 52,47 & 49,54 & 55,36 & NS & NS & NS & NS & 14,54 \\
\hline $\operatorname{DFDA}(\%)$ & 51,58 & 57,55 & 59,85 & 48,32 & 53,25 & NS & NS & NS & NS & 18,32 \\
\hline $\operatorname{MSkd}(\% / \mathrm{h})$ & 8,08 & 8,31 & 5,85 & 6,49 & 7,03 & $<0,0373$ & NS & NS & NS & 34,20 \\
\hline MSkt(h) & 13,18 & 12,86 & 21,62 & 18,62 & 17,34 & NS & NS & NS & NS & 31,82 \\
\hline FDNkd $(\% / h)$ & 4,52 & 5,12 & 3,18 & 3,00 & 4,00 & $<0,0157$ & NS & NS & NS & 27,93 \\
\hline pH ruminal & 6,16 & 6,16 & 6,33 & 6,42 & 6,63 & $<0,0003$ & NS & NS & NS & 2,81 \\
\hline
\end{tabular}

${ }^{1} 100 \mathrm{~A}-100 \%$ silagem de restos culturais do abacaxizeiro $+0 \%$ silagem de cana-de-açúcar c/0,5\% ureia 75A- $75 \%$ silagem de restos culturais do abacaxizeiro $+25 \%$ silagem de cana-de-açúcar c/0,5\% ureia 50A- 50\% silagem de restos culturais do abacaxizeiro $+50 \%$ silagem de cana-de-açúcar c/0,5\% urea $25 \mathrm{~A}-25 \%$ silagem de restos culturais do abacaxizeiro $+75 \%$ silagem de cana-de-açúcar c $/ 0,5 \%$ ureia 0A- $0 \%$ silagem de restos culturais do abacaxizeiro $+100 \%$ silagem de cana-de-açúcar c/0,5\% ureia

${ }^{2}$ Lin-linear; Quad-quadrático; Cub-cúbico; Quar-quártico $(\mathrm{P}<0,05)$

${ }^{3}$ CMS-consumo matéria seca; CMO-consumo de matéria orgânica; CFDN-consumo de fibra em detergente neutro, DMSdigestibilidade da matéria seca; DFDN- digestibilidade da fibra em detergente neutro; MSkd-taxa de desaparecimento de MS; MSkttempo de renovação de MS; FDNkd- taxa de desaparecimento de FDN

A taxa de passagem $(\% / \mathrm{h})$ tem enorme influência sobre a eficiência microbiana. A renovação mais rápida do conteúdo ruminal favorece uma população microbiana mais jovem, que tem menor exigência de manutenção e que direciona a maior parte dos nutrientes para o seu crescimento ${ }^{15}$.

Utilizando carneiros fistulados no rúmen, Varga \& Prigge $^{16}$ avaliaram o efeito de duas forrageiras (alfafa e grama) e dois níveis (alto = $90 \%$; baixo $=60 \%$ ) de ingestão e, utilizando marcadores sobre os tempos de renovação (h) para sólidos e líquidos da digesta, os autores observaram taxa média de renovação para sólidos de 5,97\%/h e tempo médio de renovação de 16,9 horas. Quanto à taxa de renovação para líquidos para os dois níveis de ingestão, foram encontrados valores respectivamente de $7,1 \% / \mathrm{h}$ e $3,1 \% / \mathrm{h}$. Neste estudo, o tempo de renovação não foi diferente $(\mathrm{P}>0,05)$ entre os tratamentos e o valor médio de $16,72 \mathrm{~h}$, similar ao observado no estudo de Varga \& Prigge ${ }^{16}$.

Houve redução $(\mathrm{P}<0,05)$ da taxa de desaparecimento da FDN (FDNkd- \%/h) entre os tratamentos (Tabela 3) com a adição de silagem de cana-de-açúcar com $0,5 \%$ de ureia. As taxas foram 4,52; 5,12; 3,18; 3,00; 4,00 , respectivamente, para os tratamentos 100A, 75A, 50A, 25A e 0A (Figura 2).

Esse efeito pode ter sido provocado pela composição química da dieta, já que a fração FDN não foi balanceada para os tratamentos, ou ainda pelo efeito associativo dos alimentos utilizados. A 
combinação entre os alimentos pode causar efeitos tanto negativo quanto positivo na digestão de carboidratos estruturais pelos ruminantes ${ }^{17}$, também pode haver preferência pela digestão dos carboidratos solúveis ou amido por parte das bactérias do rúmen, o que pode ser percebido quando há alimentos com taxa de digestão diferenciada ou com distinta velocidade de passagem.

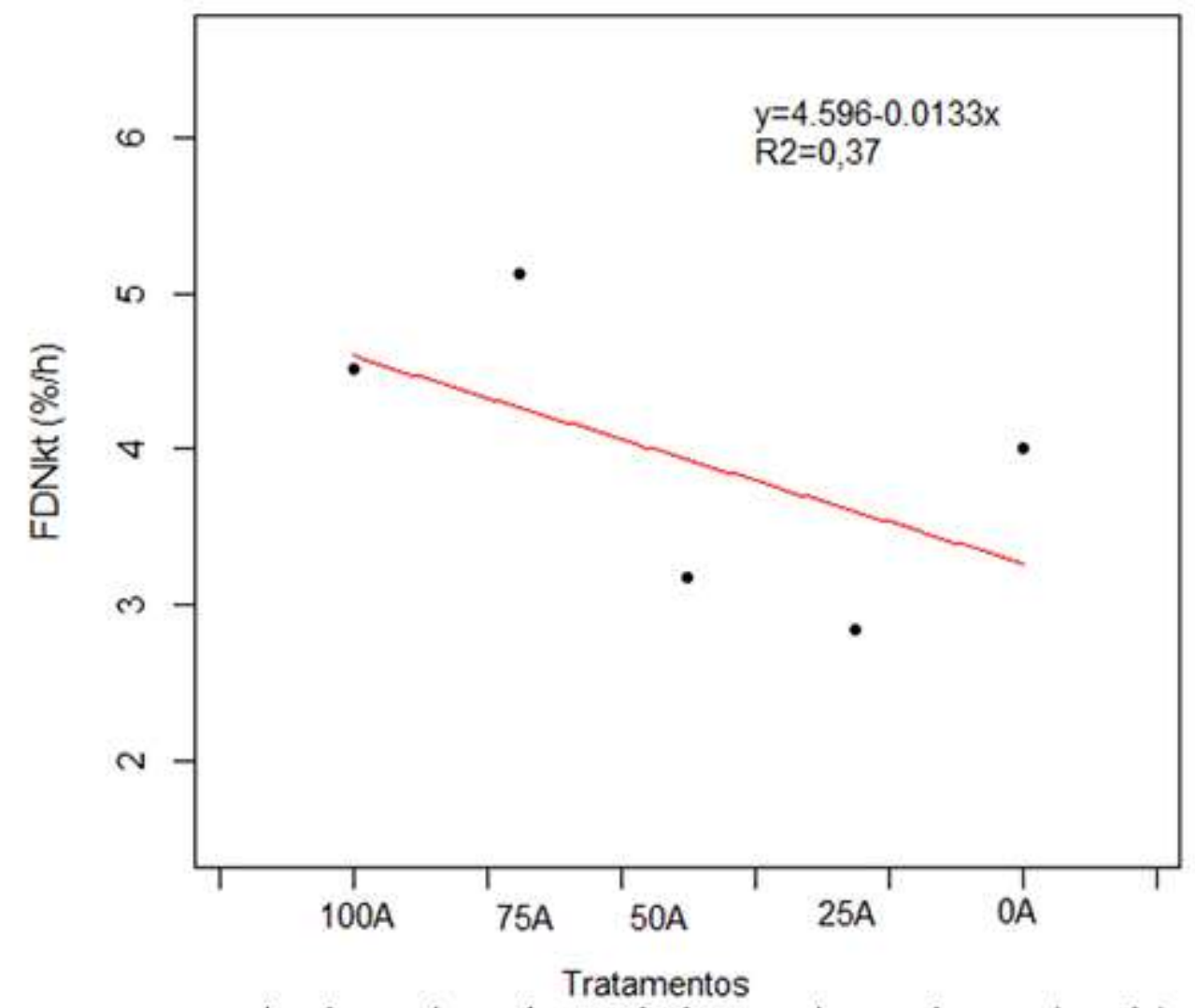

Figura 2. Equação estimada e variação da taxa de desaparecimento da FDN (FDNkt) em função da utilização de silagem de restos culturais do abacaxizeiro substituindo a silagem de cana-de-açúcar $+0,5 \%$ de ureia

Kellems et al. ${ }^{18}$, após separarem por frações (folhas verdes e secas, colmos, raízes) e analisarem as plantas do abacaxizeiro de três para quatro anos de idade, constataram média de $13,84 \%$ de amido, $7,95 \%$ de lignina, $58,42 \%$ de FDN e $33,37 \%$ de FDA. Já Carvalho et al. ${ }^{19}$ avaliaram a composição química das plantas do abacaxizeiro com idade próxima de 36 meses para determinar em quais épocas do ano são mais adequadas para o aproveitamento das folhas. Esses autores também constataram valores para o amido próximo de $13 \%$. Possivelmente, a presença do amido na SRA pode ter influenciado nesse efeito associativo dos alimentos e na variação do $\mathrm{pH}$ ruminal.

Outra possibilidade a ser considerada é da quantidade de carboidratos solúveis, uma vez que a silagem de cana-de-açúcar possui maior quantidade quando comparada à silagem de restos culturais do abacaxizeiro (Tabela 1). O principal fator que afeta a digestão dos carboidratos estruturais é a adição de carboidratos solúveis, que provocam alterações no meio ambiente do trato digestivo e na cinética do processo digestivo, como taxa de digestão, taxa de passagem das partículas, $\mathrm{pH}$ ruminal e a natureza da população microbiana ${ }^{20}$.

$\mathrm{O} \mathrm{pH}$ ruminal aumentou de forma linear (Tabela 3, Figura 3) com a adição de $\mathrm{SC}$, e os valores de 6,16;6,16;6,33;6,42;6,63 foram, respectivamente, para os tratamentos 100A, 75A, $50 \mathrm{~A}, 25 \mathrm{~A}$ e $0 \mathrm{~A}$. Uma variação de $\mathrm{pH}$ ruminal de 0,5 unidades manteria a atividade microbiana próxima do normal, e Van Soest ${ }^{5}$ relatou ainda que valores inferiores a 6,2 podem inibir a taxa de digestão e aumentar o tempo de colonização para a degradação da parede celular. 


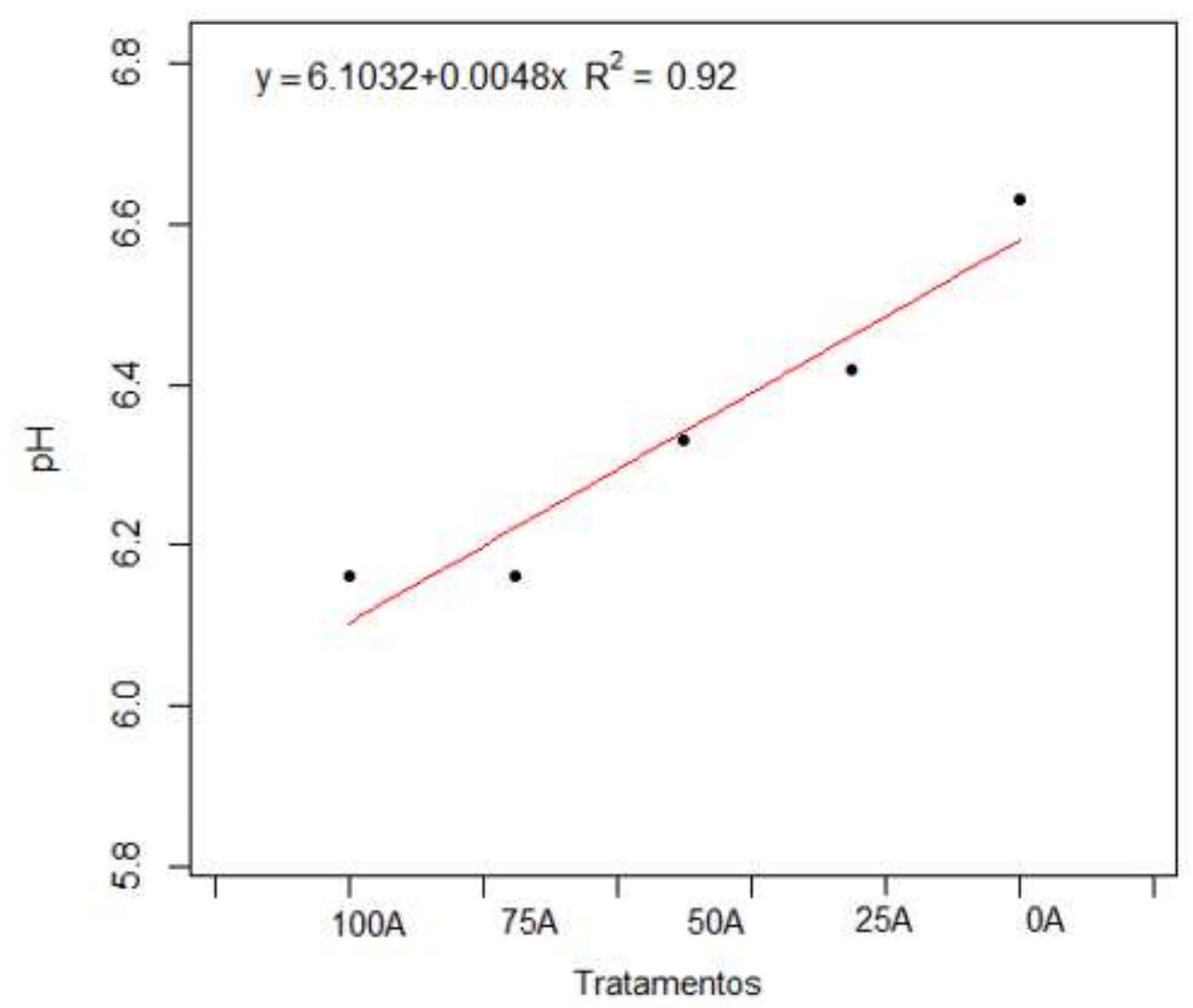

Figura 3. Equação estimada e valores do $\mathrm{pH}$ ruminal em função da utilização de silagem de restos culturais do abacaxizeiro substituindo a silagem de cana-de-açúcar $+0,5 \%$ de ureia

A eficiência microbiana também sofre interferência do $\mathrm{pH}$ ruminal e as que são mais afetadas são as bactérias fibrolíticas, fermentadoras de carboidratos fibrosos, sensíveis a valores de $\mathrm{pH}$ inferiores a 6,0. Essas bactérias são neutrofílicas, ou seja, mantém o $\mathrm{pH}$ intracelular próximo à neutralidade independentemente do $\mathrm{pH}$ extracelular ${ }^{15}$. Apesar de os valores médios de $\mathrm{pH}$ dos tratamentos 100A e 75A estarem próximos daquele limite, neste caso, possivelmente, o crescimento microbiano não foi afetado pelo $\mathrm{pH}$ ruminal.

\section{CONCLUSÃO}

Em função da taxa de desaparecimento de MS do rúmen, digestibilidade e consumo de MS pode-se utilizar a silagem de restos culturais do abacaxizeiro (SRA) em substituição à silagem de cana-de-açúcar+0,5\% ureia (SC) na alimentação de ovinos.

\section{AGRADECIMENTOS}

À empresa TORTUGA pelo apoio técnico e financeiro.

\section{REFERÊNCIAS}

1. Müller, ZO. Feeding potential of pineapple waste for cattle. World Animal Review, 1978;25(1):25-29.

2. Pedroso, AF; Nussio, LG; Loures, DRS. et al. Fermentation, losses, and aerobic stability of sugarcane silages treated with chemical and bacterial additives. Scientia Agricola. 2008;65(1):567-691.

3. Pedroso, AF; Rodrigues, AA; Junior, WB; Barbosa, PF et al. Aditivos químicos e inoculante bacteriano na ensilagem de cana-de-açúcar: efeitos sobre a fermentação das silagens e o desempenho de garrotes. Revista Brasileira de Zootecnia.[Internet] 2011;40(6):1181-1187. Disponível em: http://www.scielo.br/pdf/rbz/v40n6/04.pdf 
4. Schmidt, P.; Mari, J.L.; Nussio, L.G.; Pedroso,A.F.; Paziani, S.F.; Wechsler, F.S. Aditivos químicos e biológicos na ensilagem de cana-de-açúcar. 1. Composição química das silagens, ingestão, digestibilidade e comportamento ingestivo. Revista Brasileira de Zootecnia.[Internet] 2007;36(5):1666-1675. Disponível http://www.scielo.br/pdf/rbz/v36n5s0/a27v3650.pdf

5. Van Soest, P.J. Nutritional ecology of the ruminant. 2. ed. Ithaca: Cornell University Press, 1994. 476p.

6. Lammers, B.P.; Buckmaster, D. R.; Heinrichs, A. J. A simple method for the analysis of particle sizes of forage and total mixed rations. Journal of Dairy Science. [Internet] 1996 Oct 27;79(5):922-928. Disponível em: http://www.journalofdairyscience.org/article/S0022-

$\underline{0302(96) 76442-1 / \mathrm{pdf}}$

7. National Research Council - NRC. Nutrient requirements of domestic animals: Nutrient requirements of sheep, 6 ed. Washington: National Academy of Science, 1985. 112p.

8. Rymer, C. The measurement of forage digestibility in vivo. In: Givens, D.I., Owen, E., Axford, R.F.E. Forage evaluation in ruminant nutrition. 1 ed. London: CAB International, 2000. p.113-134.

9. Dado, R.G.; Allen, M.S. Intake limitations, feeding behavior, and rumen function of cows challenged with rumen fill from dietary fiber on inert bulk. Journal of Dairy Science [Internet] 1995 Aug 23;78(1):118-133. Disponível

http://www.journalofdairyscience.org/article/S0022-

$\underline{0302(95) 76622-X / p d f}$

10. Harvatine, D. I.; Winkler, J. E.; Devant-Guille, M.; Firkins, J. L.; St-Pierre, N. R.; Oldick, B. S.; Eastridge, M. L. Whole linted cottonseed as a forage substitute: fiber effectiveness and digestion kinetics. Journal of Dairy Science 2002 Feb 5;85(8):1988-1999. Disponível em: http://www.journalofdairyscience.org/article/S00220302(02)74275-6/pdf

11. Silva, D.J.; Queiroz, A.C. Análise de Alimentos: métodos químicos e biológicos. 3 ed. Viçosa: UFV, 2002. $235 \mathrm{p}$.

12. Mertens, D.R. Gravimetric determination of amylase treated neutral detergent fiber in feeds with refluxing in beaker or crucibles: collaborative study. Journal of AOAC International. [Internet] 2002 Feb 5;85(1):1217-1240. Disponível em: http://lib3.dss.go.th/fulltext/Journal/J.AOAC\%201999-

2003/J.AOAC2002/v85n6(nov-dec)/v85n6p1217.pdf

13. SAS Institute. Statistical Analysis System: user guide [CD-ROM]. Version 8. Cary (NC): SAS Insitute Inc., 2002.

14. Mertens, D.R.; Ely, O.L. Relationship of rate and extent of digestion to forage utilization. Journal of Animal Science. 1982;54(1):895-905.

15. Dixon, R.M.; Stockdale, C.R. Associative effects between forages and grain: consequences for feed utilization. Australian Journal Agriculture research. 1999;50(1):757-773.

16. Varga, G.A.; Prigge, E.C. Turnover Rates Influence of forage Species and Level of Intake on Ruminal. Journal of Animal Science. 1982;55(1):1498-1504.

17. Kozloski, G. V. Bioquímica dos Ruminantes. 3 ed. Santa Maria: UFSM, 2011. 214p

18. Kellems, R.O.; Wayman, O.; Nguyen, A.H. Postharvest pineapple plant forage as a potential feedstuff for beef cattle: evaluated by laboratory analyses, in vitro and in vivo digestibility and feedlot trials. Journal Animal Science. 1979;48(5):1040-1048.

19. Carvalho, V.D.; Paula, M.D.; Abreu, C.M.P; Chagas, S.J.Z. Efeito da época de colheita da planta na composição química das folhas do abacaxizeiro. Pesquisa Agropecuária Brasileira. 1991;26(1):1655-1661.

20. Fahey, G.C.; Berger, L.L. Los carbohidratos en la nutrición de los rumiantes. In: CHURCH, D.C. El rumiante. Fisiologia digestiva y nutrición. 1 ed. Zaragoza: Acribia, 1993. p.305-338. 